\title{
SSR based Genetic Diversity in MAGIC Lines of Soybean (Glycine max (L.) Merrill)
}

\author{
Bidush Ranjan Swar ${ }^{1}$, V. Swarnalatha ${ }^{2 *}$, M. Rajendar Reddy ${ }^{3}$ and S. Vanisri ${ }^{4}$ \\ ${ }^{1}$ Department of Genetics and Plant Breeding, College of Agriculture, Rajendranagar, India \\ ${ }^{2}$ Seed Research and Technology Centre, India \\ ${ }^{3} A R S$, Adilabad, India \\ ${ }^{4}$ Institute of Biotechnology, Professor Jayashankar Telangana State Agricultural University, \\ Hyderabad -500030, India \\ *Corresponding author
}

\section{A B S T R A C T}

\begin{tabular}{|l|}
\hline Key w o r d s \\
Soybean, SSR \\
markers, MAGIC \\
lines, genetic \\
diversity
\end{tabular}

Soybean MAGIC lines are recently developed tailor made source of germplasm that have undergone heavy genetic recombinations. The present study was carried out to assess its extent of genetic diversity at molecular level in 95 soybean MAGIC lines along with six checks by using 30 SSR markers from which 27 were found polymorphic. A total of 106 alleles were generated with an average of 3.53 and a range of two to six alleles per loci. The value of observed heterozygosity was varying from 0.00 to 0.099 indicating a higher frequency of homozygotes among the accessions. Maximum PIC was 0.955 for Staga001 followed by 0.948 (Satt168, Satt453, Satt534), 0.947(Satt565) and 0.945(Satt371). The range of Jaccard's similarity coefficient was varying from 0.089 to 1 , most of the values were between 0.2 to 0.3 with an average of 0.3 indicating considerable diversity exists among the genotypes. A total of six main clusters were formed by UPGMA clustering method. Cluster II was the largest comprising 48 genotypes which were grouped into four subclusters. Clustering based on SSR markers revealed a very precise grouping of the genotypes based on their relatedness than their phenotypic data alone. Hence it can be successfully deployed for selecting desirable genotypes which can be utilized in future breeding programs for exploiting heterosis or in the introgression of genes for biotic and abiotic stress tolerance in soybean crop.

\section{Introduction}

Soybean (Glycine max (L.) Merrill) is globally cultivated leading oilseed crop otherwise known as golden bean for its various nutritional qualities. The enormous economic value of soybean was realized in the first two decades of the twentieth century, therefore the crop is well known as the miracle bean of the twentieth century. In India, it was introduced 
in $1000 \mathrm{AD}$ through silk route whereas major commercial cultivation was initiated during 1960s, mostly after the launch of AICRP on soybean in 1967 (Tiwari, 2014).

Although soybean is classified as an oilseed (18-23\% oil on a moisture-free basis), its seed also contains about $38-44 \%$ protein. It is a rich source of poly unsaturated fatty acids, vitamin $B$, fibre, iron, calcium, zinc and isoflavones which substantially increases its nutritional quality. It accounts for the production of two-thirds of the world's protein concentrates for livestock feeding.

Worldwide the crop is cultivated in an area of 124.92 Mha with production of $348.71 \mathrm{MT}$ and productivity of $2791 \mathrm{Kg}$ ha-1. Globally India stands in fourth position with the cultivable area of 11.40 Mha and fifth in the production of $13.78 \mathrm{MT}$ and having a productivity of $1209 \mathrm{Kg} \mathrm{ha}^{-1}$ (FAOSTAT, 2018), which is very low in order to cater the demand of the growing population.

Due to the repetitive use of the same parents during the breeding program, the genetic base of Indian soybean cultivars has become extremely narrow. Diversity among germplasm is the most important thing to be considered before proceeding for any successful and efficient breeding program.

The study of diversity is useful for the selection of parents with wide genetic relationship for hybridization, for understanding the evolutionary pattern and to impose diversity in the breeding programs. Autogamy nature of the crop is one of the causes that hinder the genetic base of the crop to be expanded (Kumawat et al., 2015). Hence, the creation of genetic diversity in the cultivars is highly essential to carry out a successful breeding program. Multi-parent advanced generation inter-cross (MAGIC) population, an extension of advanced inter- crossed lines, is the tailor-made source of germplasm that promote inter-crossing and shuffling of the genome by involving several recombination events (Bandillo et al., 2013). It involves the use of multiple genetically diverse parents, hybridization of which leads to a population of high allelic and phenotypic diversity by several cycles of inter-mating. Thus, the MAGIC population substantially increases crop diversity and is useful for the fine mapping of QTLs due to its high allelic recombination.

Among the molecular markers particularly, SSRs are most widely used in the estimation of genetic diversity as it is more reliable, locus-specific, reproducibility, high polymorphism rate, codominant and less influenced by environmental fluctuations (Gupta and Manjaya, 2017).

Molecular characterization of germplasm accessions reveals underlying allelic diversity and the genetic base of germplasm collection (Kumawat et al., 2015). Soybean being a narrow genetic base crop, analysis of crop diversity using DNA marker is very important to reveal the exact allelic diversity among the germplasm at the molecular level.

\section{Materials and Methods}

Molecular characterization of 95 soybean MAGIC lines along with six checks such as Basara, NRC 86, JS 335, EC333901, EC546882 and EC57109 was carried out during Rabi 2019-20 at Institute of Biotechnology (IBT), College of Agriculture, PJTSAU, Rajendranagar, Hyderabad

A total of 30 soybean SSR markers distributed across 18 chromosomes were selected for genotyping all the 101 soybean MAGIC lines which are enlisted in Table 1.The assessment of molecular diversity was carried out from the SSR allelic data. 


\section{Scoring of SSR markers}

Amplified PCR products generated by SSR markers for all the soybean accessions were scored visually for the presence or absence of the corresponding DNA bands. The score ' 1 ' and ' 0 ' indicates the presence and absence of the bands, respectively. The size of the amplified PCR product was estimated with the help of image lab software of BIORAD XR ${ }^{+}$ Gel documentation system using 50bp DNA ladder as the standard size.

\section{Marker Polymorphism}

The polymorphism information content (PIC) is the value that indicates the polymorphism exists among the genotypes for a marker locus used in the linkage analysis.PIC value for each SSR marker was calculated to measure the informativeness of the markers, according to the following formula (Botstein et al., 1980).

$\mathrm{PIC}=1-\left(\sum \mathrm{P}_{\mathrm{i}}^{2}\right)$

Where,

$\mathrm{i}=$ total number of alleles detected for SSR marker

$\mathrm{P}_{\mathrm{i}}=$ frequency of the $\mathrm{i}^{\text {th }}$ allele of a particular locus

\section{Observed heterozygosity}

Observed heterozygosity indicates the proportion of individual in a population that are heterozygous for a particular locus. It was calculated by the following formula.

$$
\mathrm{H}_{\mathrm{o}}=\frac{\sum \mathrm{N}_{\mathrm{ij}}}{\mathrm{N}}
$$

Where,

$$
\mathrm{H}_{\mathrm{o}}=\text { Observed heterozygosity }
$$

$N_{i j}=$ Number of diploid individual with genotype $\mathrm{A}_{\mathrm{i}} \mathrm{A}_{\mathrm{j}}$ (Heterozygotes)

$\mathrm{N}=$ Total number of genotypes

\section{Cluster analysis}

For assessing the molecular diversity among all the soybean accessions binary data matrix (score ' 1 ' and ' 0 ') of SSR markers of all the genotype were subjected to cluster analysis using SAHN (Sequential agglomerative hierarchical non-overlapping) clustering technique performed on squared Euclidean distance matrix. Then Jaccard's coefficient was calculated using SIMQUAL (Similarity for Qualitative Data) program. The similarity coefficients were used to construct dendrogram using UPGMA (Unweighted Pair Group Method with Arithmetic mean) tool of NTSYS-pc (Numerical Taxonomy and Multivariate Analysis System) version 2.11 software (Rohlf, 1993).

\section{Results and Discussion}

\section{SSR polymorphism among all the soybean accessions}

The PCR amplification of the genomic region of 101 soybean accessions was carried out using 30 SSR markers. Twenty seven markers were polymorphic and three markers (Satt400, Satt175 and Satt618) were found to be monomorphic. The per cent polymorphism was observed to be $90 \%$ for all the markers indicating the presence of variable SSR loci in the studied soybean accessions. A total of 106 alleles were generated with an average of 3.53 and a range of two to six alleles per loci. A maximum of six alleles were generated by Staga001 and a minimum of two alleles were detected by four markers namely Satt289, Satt162, Satt538 and Satt481. The amplified PCR product size was ranging from 95 to 350 base pairs. The mean observed heterozygosity 
(Ho) and the mean polymorphic Information content (PIC) were observed to be 0.03 and 0.79 respectively.

\section{Observed heterozygosity (Ho) and Polymorphic Information content (PIC)}

The heterozygosity of a marker is the likelihood of an individual being heterozygous at the marker site and depends on the number of alleles and their frequency in the population (Serrote et al., 2020). It provides an overall picture of the presence of heterozygote individuals in the population. Soybean being a self-pollinated crop observed heterozygosity is likely to be very less. The range of observed heterozygosity was varying from 0.00 to 0.099 (Table 2). The maximum heterozygosity was shown by the marker staga001 (0.099), followed by Satt126 (0.089), Satt619 (0.079), Satt168 (0.079) and Satt523 (0.059). The complete homozygosity was recorded in seven markers including monomorphic markers viz., Satt162, SOYGPATR, Satt463, Satt143, Satt400, Satt175, Satt618. The result revealed presence of less heterozygosity in the SSR markers used to assess the genetic diversity. Similarly, the lower value of heterozygosity for soybean was obtained by Mulato et al., (2010), Bisen et al., (2014) and Gupta and Manjaya (2017).

Polymorphism information content (PIC) value measures the ability of a marker to detect polymorphism among the individuals of a population. It is the reflection of allelic diversity and their frequency among the accessions. The microsatellite marker exhibits higher PIC value due to their co-dominant and multi-allelic nature. The PIC values are considered as highly informative (more than 0.5 ), informative (between 0.25 and 0.5 ) and are less informative if less than 0.25 (Botstein et al., 1980). In the present study, maximum PIC (0.955) was observed for the marker Staga001 followed by (Satt168, Satt453,
Satt534) (0.948), Satt565 (0.947) and Satt371 (0.945). The minimum value of PIC was observed to be zero for Satt400, Satt175 and Satt618. Among all the markers, PIC values were found to be more than 0.5 in 27 markers and were considered to be highly informative for carrying out polymorphism study. Similar results for higher PIC values for the markers were reported by $\mathrm{Fu}$ et al., (2007), Hu et al., (2014) and Gupta and Manjaya (2017). The values of PIC for all the markers are presented in Fig. 1.

\section{Genetic similarity coefficient among all the soybean cultivars}

The estimation of genetic similarity between the individuals is an important and decisive point for clustering and analysing the extent of diversity present among the genotypes within a population (Kosman and Leonard, 2005). Jaccard's similarity coefficient is most widely used to compute the genetic relationship among the cultivars so as to grouping them into various clusters.

Among all the soybean accessions a total of 5050 pairs of Jaccard's similarity coefficients were computed. The range of similarity coefficient was observed varying from 0.089 to 1. However, most of the values were between 0.2 to 0.3 with an average of 0.3 indicating considerable diversity exists among the genotypes.

The distribution pattern of all the similarity coefficient is indicating a very low level of genetic similarity among the soybean accessions which may have resulted due to the genetic recombination and gene reshuffling during the development of MAGIC lines. The result revealed a low value of average similarity coefficient which is in agreement with the result obtained by Xie et al., (2005), Mimura et al., (2007) and Chauhan et al., (2015). 
Table.1 List of SSR markers used for genotyping 101 soybean accessions

\begin{tabular}{|c|c|c|}
\hline S. No. & Markers & Markers sequence \\
\hline \multirow[t]{2}{*}{1} & Staga001 Forward & GCGGAGGGGAGTTTGCAGATTA \\
\hline & Staga001 Reverse & GCGGCAAGGGCAACTGAAAAAT \\
\hline \multirow[t]{2}{*}{2} & Satt720 Forward & GCGCATATACGAAACATATTGTCAAGTTACA \\
\hline & Satt720 Reverse & GCGTCATGAGTGGTTTGTTCTATACTTCTAT \\
\hline \multirow[t]{2}{*}{3} & Satt656 Forward & GCGTACTAAAAATGGCAATTATTTGTTG \\
\hline & Satt656 Reverse & GCGTGTTTCAGTATTTGGATAATAGAAT \\
\hline \multirow[t]{2}{*}{4} & Satt666 Forward & TGGCTTGTCATCTCTACTTTTATTAG \\
\hline & Satt666 Reverse & TCATGCATCTAATTTGTTTTATCTATCA \\
\hline \multirow[t]{2}{*}{5} & Satt686 Forward & ACGGAAAATAAATGAAACTAAGA \\
\hline & Satt686 Reverse & GCGCTATCAGATAGAGAAGCAGAAGAAT \\
\hline \multirow[t]{2}{*}{6} & Satt631 Forward & GGTAGATCCAGGAGCTTGAGTCAG \\
\hline & Satt631 Reverse & GCGCATCTCACTGCACTTGATTTT \\
\hline \multirow[t]{2}{*}{7} & Satt126 Forward & GCTTGGTAGCTGTAGGAA \\
\hline & Satt126 Reverse & ATAAAACAAATTCGCTGATAT \\
\hline \multirow[t]{2}{*}{8} & Satt129 Forward & TTCAGTACAAGTCGGGTGAATAATAATA \\
\hline & Satt129 Reverse & TTCAGTACAAGTCGGGTGAATAATAATA \\
\hline \multirow[t]{2}{*}{9} & Satt168 Forward & CGCTTGCCCAAAAATTAATAGTA \\
\hline & Satt168 Reverse & ССАТТСТССААССТСААТСТТАТАТ \\
\hline \multirow[t]{2}{*}{10} & Satt289 Forward & GCGCCCAGGTTTAAAAGT \\
\hline & Satt289 Reverse & CTGCCCCATCACTAGCCCTTCTT \\
\hline \multirow[t]{2}{*}{11} & Satt286 Forward & GCGGCGTTAATTTATGCCGGAAA \\
\hline & Satt286 Reverse & GCGTTTGGTCTAGAATAGTTCTCA \\
\hline \multirow[t]{2}{*}{12} & Satt371 Forward & TGCAAACTAACTGGATTCACTCA \\
\hline & Satt371 Reverse & GAGATCCCGAAATTTTAGTGTAACA \\
\hline \multirow[t]{2}{*}{13} & Satt453 Forward & GCGGAAAAAAAACAATAAACAACA \\
\hline & Satt453 Reverse & TAGTGGGGAAGGGAAGTTACC \\
\hline \multirow[t]{2}{*}{14} & Satt534 Forward & CTCCTCCTGCGCAACAACAATA \\
\hline & Satt534 Reverse & GGGGGATCTAGGCCATGAC \\
\hline \multirow[t]{2}{*}{15} & Satt565 Forward & GCGCCCGGAACTTGTAATAACCTAAT \\
\hline & Satt565 Reverse & GCGCTCTCTTATGATGTTCATAATAA \\
\hline \multirow[t]{2}{*}{16} & Satt162 Forward & GGGAAGAAGTATATGCTACATCAA \\
\hline & Satt162 Reverse & GGGTTAATTTTTATCTTCTAATAGTTT \\
\hline \multirow[t]{2}{*}{17} & Satt619 Forward & GGCAGAACTAGTACGCTTCTGATT \\
\hline & Satt619 Reverse & GCGGTTAAGCATAATAGATCAGCCT \\
\hline \multirow[t]{2}{*}{18} & SOYGPATR Forward & GGAAGAAAGTATTGGTCTGT \\
\hline & SOYGPATR Reverse & AGGAGAGAGTGGAGAGATTA \\
\hline \multirow[t]{2}{*}{19} & Satt523 Forward & GCGATTTCTTCCTTGAAGAATTTTCTG \\
\hline & Satt523 Reverse & GCGCTTTTTCGGCTGTTATTTTTAACT \\
\hline \multirow[t]{2}{*}{20} & Satt389 Forward & GCGGCTGGTGTATGGTGAAATCA \\
\hline & Satt389 Reverse & GCGCCAAAACCAAAAGTTATATC \\
\hline
\end{tabular}




\begin{tabular}{|c|c|c|}
\hline \multirow[t]{2}{*}{21} & Satt600 Forward & GCGCAGGAAAAAAAAACGCTTTTATT \\
\hline & Satt600 Reverse & GCGCAATCCACTAGGTGTTAAT \\
\hline \multirow[t]{2}{*}{22} & Satt598 Forward & CGATTTGAATATACTTACCGTCTATA \\
\hline & Satt598 Reverse & CACAATACCTGTGGCTGTTATACTAT \\
\hline \multirow[t]{2}{*}{23} & Satt538 Forward & GCAGGCTTATCTTAAGACAAGT \\
\hline & Satt538 Reverse & GGGGCGATAAACTAGAACAGGA \\
\hline \multirow{2}{*}{24} & Satt481 Forward & GGGTTAACCGTCCACACATCTATT \\
\hline & Satt481 Reverse & GACGGTTTTAAACGGTAAGAAAAT \\
\hline \multirow{2}{*}{25} & Satt463 Forward & TTGGATCTCATATTCAAACTTTCAAG \\
\hline & Satt463 Reverse & CTGCAAATTTGATGCACATGTGTCTA \\
\hline \multirow[t]{2}{*}{26} & Satt143 Forward & GTGCCACAAATTTAAAATTACTCA \\
\hline & Satt143 Reverse & TCССТCССТTTTGATTTACAC \\
\hline \multirow[t]{2}{*}{27} & Satt400 Forward & TTGGTCATCAAACTGTTA \\
\hline & Satt400 Reverse & CATAAGGGGTCCCACTCTA \\
\hline \multirow{2}{*}{28} & Satt175 Forward & GACCTCGCTCTCTGTTTCTCAT \\
\hline & Satt175 Reverse & GGTGACCACСССТАТTCСТTAT \\
\hline \multirow[t]{2}{*}{29} & Satt618 Forward & GCGGTGATATTACCCCAAAAAAATGAA \\
\hline & Satt618 Reverse & GCGCTAGTTTCTAGTGGAAAGATGAGT \\
\hline \multirow{2}{*}{30} & Satt184 Forward & GCGCTATGTAGATTATCCAAATTACGC \\
\hline & Satt184 Reverse & GCCACTTACTGTTACTCAT \\
\hline
\end{tabular}

Fig.1 Polymorphic Information content (PIC) of all the 30 SSR markers

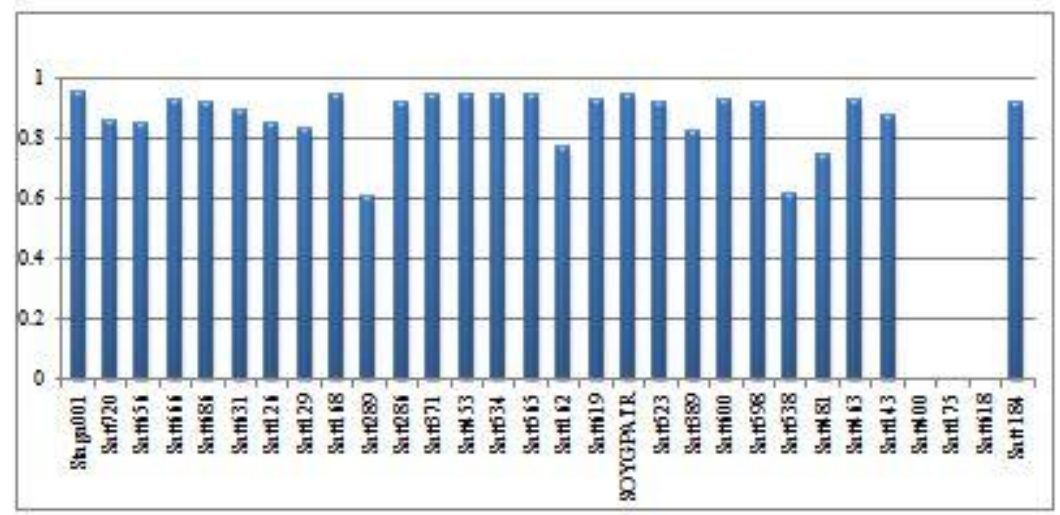


Table.2 Molecular profile of 101 soybean accessions generated by 30 SSR markers

\begin{tabular}{|c|c|c|c|c|c|c|c|}
\hline S. No. & Markers & $\begin{array}{l}\text { Allelic } \\
\text { size } \\
\text { (bp) }\end{array}$ & $\begin{array}{c}\text { Chromoso } \\
\text { me } \\
\text { number }\end{array}$ & $\begin{array}{c}\text { Linkage } \\
\text { group }\end{array}$ & $\begin{array}{c}\text { Numbe } \\
\text { r of } \\
\text { alleles }\end{array}$ & $\begin{array}{c}\text { Observed } \\
\text { heterozygosit } \\
y\end{array}$ & PIC \\
\hline 1 & Staga001 & $200-300$ & 6 & $\mathrm{C} 2$ & 6 & 0.0396 & 0.955 \\
\hline 2 & Satt720 & $270-305$ & 15 & $\mathrm{E}$ & 3 & 0.0396 & 0.859 \\
\hline 3 & Satt656 & $120-155$ & 13 & $\mathrm{~F}$ & 3 & 0.0396 & 0.852 \\
\hline 4 & Satt666 & $200-265$ & 12 & $\mathrm{H}$ & 5 & 0.0198 & 0.929 \\
\hline 5 & Satt686 & $290-350$ & 16 & $\mathbf{J}$ & 4 & 0.0594 & 0.914 \\
\hline 6 & Satt631 & $110-160$ & 3 & $\mathrm{~N}$ & 4 & 0.0297 & 0.895 \\
\hline 7 & Satt126 & $110-160$ & 14 & B2 & 3 & 0.0891 & 0.846 \\
\hline 8 & Satt129 & $110-140$ & 1 & D1a & 3 & 0.0198 & 0.835 \\
\hline 9 & Satt168 & $140-200$ & 14 & B2 & 5 & 0.0792 & 0.948 \\
\hline 10 & Satt289 & $200-240$ & 6 & $\mathrm{C} 2$ & 2 & 0.0198 & 0.608 \\
\hline 11 & Satt286 & $200-250$ & 6 & $\mathrm{C} 2$ & 4 & 0.0198 & 0.917 \\
\hline 12 & Satt371 & $240-300$ & 6 & $\mathrm{C} 2$ & 5 & 0.0099 & 0.945 \\
\hline 13 & Satt453 & $210-270$ & 11 & B1 & 5 & 0.0297 & 0.948 \\
\hline 14 & Satt534 & $145-210$ & 14 & B2 & 5 & 0.0495 & 0.948 \\
\hline 15 & Satt565 & $160-225$ & 4 & $\mathrm{C} 1$ & 5 & 0.0297 & 0.947 \\
\hline 16 & Satt162 & $260-300$ & 20 & I & 2 & 0 & 0.768 \\
\hline 17 & Satt619 & $110-140$ & 5 & A1 & 4 & 0.0792 & 0.928 \\
\hline 18 & SOYGPATR & $95-125$ & 4 & C1 & 5 & 0 & 0.943 \\
\hline 19 & Satt523 & $150-190$ & 19 & $\mathrm{~L}$ & 4 & 0.0594 & 0.922 \\
\hline 20 & Satt389 & $200-250$ & 17 & D2 & 3 & 0.0495 & 0.824 \\
\hline 21 & Satt600 & $150-240$ & 2 & D1b & 5 & 0.099 & 0.926 \\
\hline 22 & Satt598 & $150-190$ & 15 & $\mathrm{E}$ & 4 & 0.0297 & 0.921 \\
\hline 23 & Satt538 & $100-110$ & 8 & A2 & 2 & 0.0099 & 0.613 \\
\hline 24 & Satt481 & $145-155$ & 19 & $\mathrm{~L}$ & 2 & 0.0099 & 0.743 \\
\hline 25 & Satt463 & $150-190$ & 7 & M & 4 & 0 & 0.928 \\
\hline 26 & Satt143 & $190-220$ & 19 & $\mathrm{~L}$ & 3 & 0 & 0.878 \\
\hline 27 & Satt400 & 205 & 18 & $\mathrm{G}$ & 1 & 0 & 0 \\
\hline 28 & Satt175 & 160 & 7 & $\mathrm{M}$ & 1 & 0 & 0 \\
\hline 29 & Satt618 & 260 & 7 & M & 1 & 0 & 0 \\
\hline 30 & Satt184 & $140-175$ & 1 & D1a & 3 & 0.0099 & 0.921 \\
\hline
\end{tabular}


Fig.2 Dendrogram of 101 soybean accessions by UPGMA clustering method using Jaccard's similarity coefficient

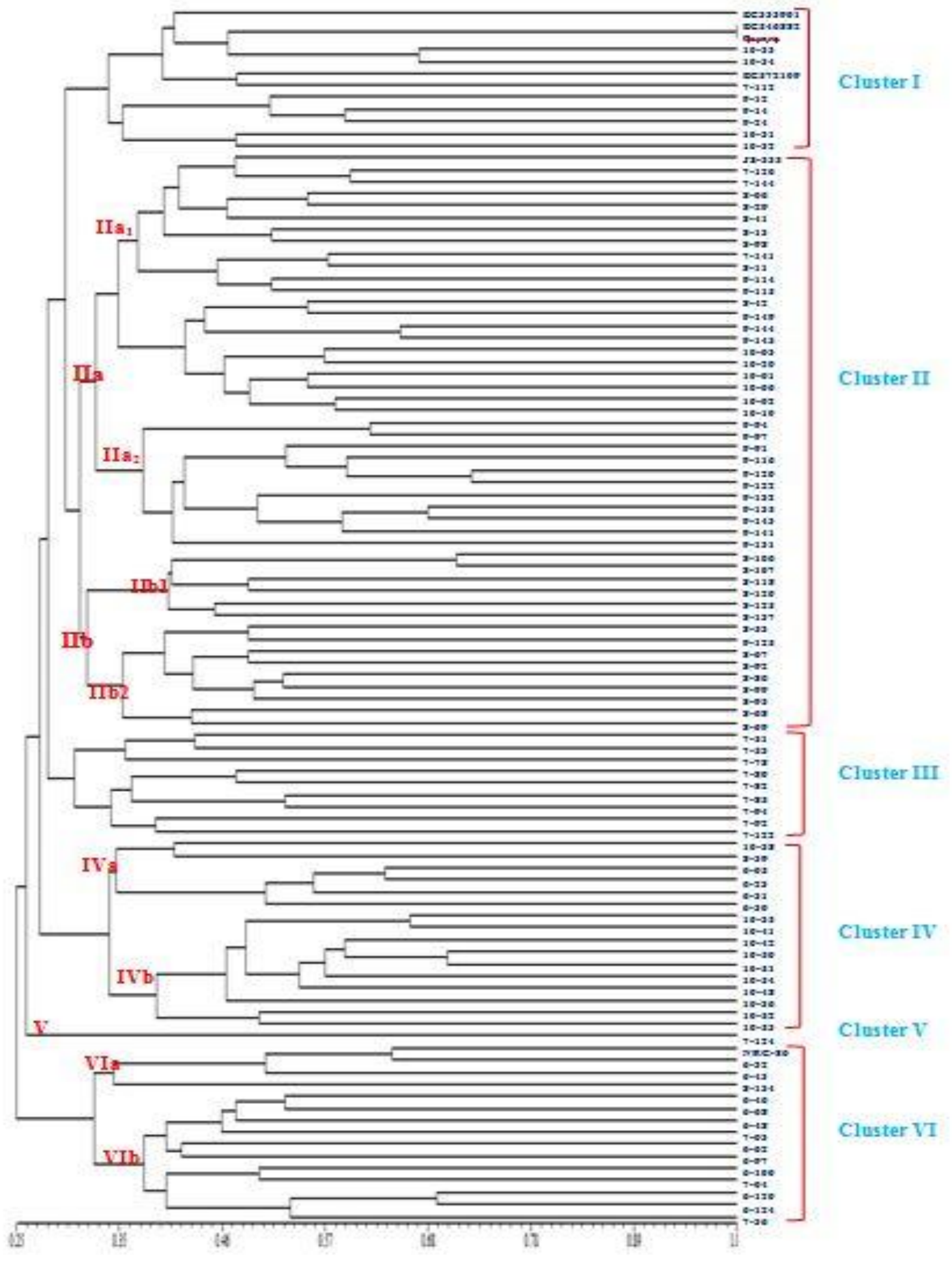


Table.3 Clusters formed by 101 soybean genotypes using UPGMA and SAHN clustering

\begin{tabular}{|c|c|c|}
\hline Cluster & Genotypes included & Total \\
\hline Cluster I & $\begin{array}{l}\text { EC333901, EC546882, Basara, 10-33, 10-34, EC572109, 7-112, 9-12, 9-14, } \\
\text { 9-24, 10-31, 10-32 }\end{array}$ & 12 \\
\hline Cluster IIa $_{1}$ & $\begin{array}{l}\text { JS 335, 7-126, 7-144, 8-06, 8-29, 8-41, 8-13, 8-98, 7-141, 8-11, 9-114, 9- } \\
115,8-42,9-149,9-144,9-145,10-03,10-20,10-01,10-06,10-02,10-10\end{array}$ & 22 \\
\hline Cluster IIa 2 & $9-94,9-97,9-91,9-116,9-120,9-122,9-132,9-135,9-143,9-141,9-131$ & 11 \\
\hline Cluster II $\mathbf{b}_{1}$ & $8-106,8-107,8-118,8-120,8-125,8-137$ & 6 \\
\hline Cluster $\mathbf{I I b}_{2}$ & $8-53,9-125,8-67,8-92,8-86,8-99,8-95,8-68,8-69$ & 9 \\
\hline Cluster III & $7-51,7-53,7-78,7-80,7-82,7-85,7-94,7-92,7-122$ & 9 \\
\hline Cluster $I_{V_{\mathrm{a}}}$ & $10-38,8-39,6-05,6-23,6-31,6-30$ & 6 \\
\hline Cluster $I_{V_{b}}$ & $10-35,10-41,10-42,10-50,10-51,10-54,10-48,10-36,10-52,10-53$ & 10 \\
\hline Cluster V & $7-124$ & 1 \\
\hline Cluster $\mathbf{V I}_{\mathbf{a}}$ & NRC $86,6-32,6-43,8-134$ & 4 \\
\hline Cluster $\mathbf{V I}_{\mathbf{b}}$ & $6-46,6-68,6-48,7-03,6-62,6-97,6-100,7-04,6-120,6-124,7-36$ & 11 \\
\hline
\end{tabular}

\section{Cluster analysis}

Cluster analysis is a very useful technique in computing the genetic relationships among the populations of diverse origins in a simplified manner. It is also effective in indicating accessions with useful traits belonging to different clusters for hybridization. In the present study, the molecular diversity was computed by UPGMA (Unweighted Pair Group Method with Arithmetic mean) and SAHN (Sequential, Agglomerative, Hierarchical and Nested) clustering algorithm of NTSYS-pc version 2.02 software (Rohlf, 1993). The dendrogram was constructed using Jaccard's similarity coefficients among all the pairs of genotypes based on SSR marker data. The average of all the pairs of similarity coefficient among the genotypes was found to be 0.3 at which the cut-off line was drawn to calculate the number of clusters. The dendrogram (Fig. 2) reveals a significant amount of diversity among the accessions that grouped them into six main clusters and is presented in Table 3.

Cluster I was formed at 0.34 Jaccard's similarity coefficient which comprised 12 number of genotypes. A total of four checks (EC333901, EC546882, Basara and EC572109) along with eight MAGIC lines were grouped into it indicating that these checks have distinct genotypic composition than rest of the accessions. Cluster II was found to be the largest comprised of 48 genotypes which formed at 0.3 similarity coefficient. The cluster II was grouped into two sub-clusters viz., IIa and IIb which were further grouped into $\mathrm{IIa}_{1}, \mathrm{IIa}_{2}$, and $\mathrm{IIb}_{1}, \mathrm{IIb}_{2}$ respectively. These four sub-clusters were formed at $0.35,0.37,0.40$ and 0.35 similarity coefficient respectively. The sub-cluster $\mathrm{IIa}_{1}$ had a total of 21 MAGIC lines belongs to the series 7 (7-126, 7-144, 7-141), 8 (8-06, 8-29, 8-41, 8-13, 8-42, 8-98, 8-11), 9 (9-114, 9-115, 9-149, 9-144, 9-145) and $10(10-03,10-20$, $10-01,10-06,10-02,10-10)$ including the check JS 335. The grouping suggests some amount of similarities among the MAGIC lines with JS 335 which may have resulted during the MAGIC pedigree development. The sub-cluster $\mathrm{IIa}_{2}$ had a total of 11 MAGIC lines belongs to the series 9 . The sub-cluster $\mathrm{IIb}_{1}$ was formed at similarity coefficient 0.4 , comprised of six MAGIC lines belongs to the series 8 (8-106, 8-107, 8-118, 8-120, 8-125, 8- 
137). Similarly, nine accessions (8-53, 9-125, 8-67, 8-92, 8-86, 8-99, 8-95, 8-68, 8-69) were grouped together in cluster $\mathrm{IIb}_{2}$. Cluster III had nine accessions which was formed at similarity coefficient 0.35 . The cluster IV (16 accessions) was formed at the similarity coefficient 0.34 which was further grouped into IVa ( 6 genotypes) and IVb (10 genotypes) with similarity coefficient 0.35 and 0.39 respectively. Cluster V was found to be a solitary cluster formed at similarity coefficient of 0.26 . It contained a single genotype namely, 7-124 indicating its distinctness from the rest of the accessions. Cluster VI was formed at similarity coefficient 0.32 and was grouped into two sub-clusters namely, VIa and VIb formed at similarity coefficient 0.34 and 0.37 respectively. The genotypes belong to cluster VIa was NRC-86, 6-32, 6-43, 8-134. Similarly, a total of 11 MAGIC lines of series 6 (6-46, 6-68, 6-48, 6-62, 6-97, 6-100, 6-120, 6-124) and 7 (7-36, 7-03, 7-04) were included in the cluster $\mathrm{VIb}$ indicating a considerable amount of similarity exist among these genotypes. Soybean MAGIC lines belong to the same series were usually grouped together indicating a better similarity among these genotypes. Three founder parents (EC333901, EC546882, EC572109) and the check Basara, were clustered separately from majority of the accessions indicating that the studied MAGIC lines have undergone several new cross combinations which were found to be genetically less similar to their founder parents and are also less similar to each other as they have average similarity coefficient of 0.3 . Hence the selected MAGIC lines are considered to be highly variable and diverse which can be utilized in the further crop improvement program.

\section{References}

Bandillo, N., Raghavan, C., Muyco, P. A., Sevilla, M. A. L., Lobina, I. T., DillaErmita, C. J., Tung, C. W., McCouch,
S., Thomson, M., Mauleon, $\mathrm{R}$ and Singh, R. K., 2013. Multi-parent advanced generation inter-cross (MAGIC) populations in rice: progress and potential for genetics research and breeding. Rice. 6(1): 1-15.

Bisen, A., Khare, D., Nair, P and Tripathi, N. 2014. SSR analysis of 38 genotypes of soybean (Glycine Max (L.) Merr.) genetic diversity in India. Physiology and Molecular Biology of Plants. 21(1): 109-115.

Botstein, D., White, R. L., Skolnick, M and Davis, R. W. 1980. Construction of a genetic linkage map in man using restriction fragment length polymorphisms. American Journal of Human Genetics.32: 314- 331.

Chauhan, D. K., Bhat, J. A., Thakur, A. K., Kumari, S., Hussain, $\mathrm{Z}$ and Satyawathi, C. T. 2015. Molecular characterization and genetic diversity assessment in soybean [Glycine max (L.) Merr.] varieties using SSR markers. Indian Journal of Biotechnology. 14: 504-510.

Food and Agriculture Organization of the United Nations. Faostat.2018. https://www.fao.org/faostat/en/\#data/Q C.

Gupta, S and Manjaya, J. 2017. Genetic diversity and population structure of Indian soybean [Glycine max (L.) Merr.] revealed by simple sequence repeat markers. Journal of Crop Science and Biotechnology.20(3): 221230.

Hu, Z., Kan, G., Zhang, G., Zhang, D., Hao, D and $\mathrm{Yu}, \mathrm{D}$. 2014. Genetic diversity analysis using simple sequence repeat markers in soybean. Plant Genetic Resources. 12(1): S87-S90.

Kosman, E and Leonard, K. J. 2005. Similarity coefficients for molecular markers in studies of genetic relationships between individuals for 
haploid, diploid, and polyploid species. Molecular ecology. 14(2): 415-424.

Kumawat, G., Singh, G., Gireesh, C., Shivakumar, M., Arya, M., Agarwal, D. K and Husain, S. M. 2015. Molecular characterization and genetic diversity analysis of soybean (Glycine $\max (\mathrm{L}$.)Merr.) germplasm accessions in India. Physiology and Molecular Biology of Plants. 21(1): 101-106.

Mimura, M., Coyne, C. J., Bambuck, M. W and Lumpkin, T.A. 2007. SSR diversity of vegetable soybean [Glycine max (L.) Merr.]. Genetic Resources and Crop Evolution. 54(3): 497-508.

Mulato, B. M., Möller, M., Zucchi, M.I., Quecini, V and Pinheiro, J.B., 2010. Genetic diversity in soybean germplasm identified by SSR and
EST-SSR markers. Pesquisa Agropecuária Brasileira. 45(3): 276283.

Rohlf, F. J. 1993. NTSYS-PC. Numerical taxonomy and multivariate analysis system. New York. 1: 3-4.

Serrote, C. M. L., Reiniger, L. R. S., Silva, K. B., dos Santos Rabaiolli, S. M and Stefanel, C.M. 2020. Determining the Polymorphism Information Content of a molecular marker. Gene. 726: 1-18.

Tiwari, S.P. 2014. Raising the yield ceiling in soybean-An Indian overview. Soybean Research. 12(2): 1-43.

Xie, H., Guan, R., Chang, R and Qiu, L. 2005. Genetic diversity of Chinese summer soybean germplasm revealed by SSR markers. Chinese Science Bulletin. 50(6): 526-535.

\section{How to cite this article:}

Bidush Ranjan Swar, V. Swarnalatha, M. Rajendar Reddy and Vanisri, S. 2021. SSR based Genetic Diversity in MAGIC Lines of Soybean (Glycine max (L.) Merrill). Int.J.Curr.Microbiol.App.Sci. 10(04): 116-126. doi: https://doi.org/10.20546/ijcmas.2021.1004.011 